\title{
Research Square \\ Protein Digestibility and Biochemical \\ Characteristics of Soybean in Three Conditions of Fermentation Processing Step: An in Vitro Study
}

\section{Sunantha Ketnawa}

Chiba University

Yukiharu Ogawa ( $\nabla$ ogwy@faculty.chiba-u.jp )

Chiba University

\section{Research Article}

Keywords: soybean, amino acids, bioactivities

Posted Date: February 1st, 2021

DOl: https://doi.org/10.21203/rs.3.rs-154250/v1

License: (c) (i) This work is licensed under a Creative Commons Attribution 4.0 International License.

Read Full License

Version of Record: A version of this preprint was published at Scientific Reports on July 9th, 2021. See the published version at https://doi.org/10.1038/s41598-021-93451-x. 


\section{Title}

2 Protein digestibility and biochemical characteristics of soybean in three conditions of

3 fermentation processing step: An in vitro study

4

\section{Authors' names and affiliations}

6 Sunantha Ketnawa, Yukiharu Ogawa*

7

8 Graduate School of Horticulture, Chiba University, 648, Matsudo, Matsudo 271-8510, Japan 9

$10{ }^{*}$ Corresponding author

11 Y. Ogawa, e-mail: ogwy@faculty.chiba-u.jp, tel: +81-47-308-8848 


\section{Abstract}

13 Protein digestibility of soybean (soaked "S", boiled "B", and fermented "F" soybeans) was

14 changed as $20.58 \pm 0.25 \%, 48.71 \pm 0.04 \%$, and $50.21 \pm 0.45 \%$, respectively in the preparation of soybean fermentation. After simulated digestion, the increment rate of protein digestibility of both $\mathrm{B}$ and $\mathrm{F}$ was comparable and higher than that of $\mathrm{S}$ accompanying by the accumulations of small protein sub-fractions and essential amino acids. Interestingly, bioactivity parameters of all digested fractions increased by around 2 to 4 -fold when digestion stages were progressed with overall $\mathrm{F}$ showed the maximum values. Processing not only improves the palatability but also increases protein utilization, the bioavailability of nutrients, and healthy support. The study verified the effect of processing and the benefits of soybean and fermented soybean beyond their basic nutrients which could be claimed as functional foods with higher protein digestibility and indispensable amino acids as well as potential bioactivities. 


\section{Introduction}

A fermented soybean using pure cultured Bacillus subtilis subsp. natto, is called "natto", one of the Japanese traditional plant-based fermented foods. Natto is comprised of fundamental nutrients, i.e. dietary fiber, isoflavones, linoleic acid, vitamins, and some minerals as well as some bioactive substances namely nattokinase (a fibrinolytic agent), gamma-polyglutamic acid ( $\mathrm{Y}$-PGA), and bioactive peptides. ${ }^{1}$ The beneficial attributes of natto might be concerned with enzymatically degraded polymeric substances from soluble solids, in particular, soluble nitrogenous compounds from fermentation by $B$. subtilis proteases which hydrolyze soy protein into oligopeptides and short-chain peptides during fermentation. ${ }^{2}$ This can promote an improvement in protein digestibility, a reduction in anti-nutritional factors as well as hydrolysis of oligosaccharides (stachyose and raffinose). ${ }^{3}$ Natto quality mainly depends on the conditions of soaking, cooking, fermentation bacteria strain and soybean cultivars. The degree and speed of the reactions, and substances, enzymes, amino acids and peptides released during fermentation process also affect natto characteristics and flavor. ${ }^{4}$ Apart from aforementioned factors, digestive system significantly alters the release of new active fragments that present higher or lower bioactivity than raw materials after consumption. González Montoya et al. ${ }^{5}$ demonstrated estimating protein availability for intestinal absorption after digestion can be evaluated from protein digestibility which reflecting the efficiency of utilization of dietary protein. The more peptide bonds are broken, the more proteins are hydrolyzed and so the lower molecular weight (MW) of oligopeptides and the more free amino acids produced ${ }^{6}$ Amino acid profile is another vital factor in evaluating the protein nutritive quality. The digestion of that protein into small peptides and free amino acids is the principal parameter of the absorption of its amino acids by the human body. ${ }^{7}$ As a result of hydrolysis of soybean proteins (Glycinin and $\beta$-conglycinin) during fermentation or digestion, bioactive peptides are produced. They may exhibit bioactive properties and act like regulatory compounds for instance antioxidant, anti-diabetic, antihypertensive, antimicrobial, anti-inflammatory and prevention of cancer and gastrointestinal 
disorders. ${ }^{4}$ Besides, natto consumption contributes to improvement of the intestinal flora on both the composition and the metabolites aspect. Additionally, the odor of the faces was slightly reduced when consumed regularly which related to protein digestion and metabolic activity of the human fecal flora. ${ }^{8}$

Nowadays, information on benefits of natto products is extensive. However, the information on changes in biochemical characteristics (i.e. soluble peptides, protein digestibility, amino acids and total phenolic content) and potential health benefits (i.e. antioxidant activity and anti-inflammatory activity) for soybeans at different conditions for fermentation processing, i.e. soaking, boiling and fermentation is limited. It is also essential to verify whether protein become easier digestible at which fermentation processing steps as well as biochemical properties. The purpose of this study is to investigate the effect of fermentation processing, i.e. soaking (as uncooked), boiling (as cooked) and fermentation steps, on the protein digestibility of soybeans using a simulated in vitro gastrointestinal digestion technique. Digested fractions from three soybean conditions during simulated digestion were also investigated for the evaluation of potential health benefits such as antioxidant activity and in vitro anti-inflammatory activity.

\section{Results and discussion}

\section{Simulated in vitro digestion parameters}

Figure 1 displays the variability in TSN (\%), yield of TCA-soluble peptides ( $\mathrm{mg} / \mathrm{mL})$, SDSPAGE profile and free amino acid composition determined as well as the protein digestibility (\%) compared to total protein content in soaked soybeans (S). The digested fraction (freezedried powder) of B showed the most TSN content followed by that in $\mathrm{F}$ and $\mathrm{S}$ as shown in Figure 1. TSN content stability during simulated digestion was slightly increased in F (5.14$7.82 \%)$ and $B(7.20-8.53 \%)$ and quite stable in S (6.43-6.32\%). Nitrogen content rose approximately 1.20 -fold between before and after simulated digestion in $\mathrm{F}$ and $\mathrm{B}$. The increase of nitrogen content proved that more nitrogen was released during stimulated 
digestion. The higher nitrogen content in $\mathrm{F}$ than that in $\mathrm{S}$ may have been generated from hydrolysis by bacterial fermentation. Previous studies have shown that an increase in soluble and dialyzable material is caused by biochemical changes in the substrate from fermentation of soybeans using several Bacillus spp. ${ }^{6}$ Investigations of the level of protein and carbohydrate breakdown in fermented soybean by Lee et al. ${ }^{14}$ revealed the major breakdown of polymers into water-soluble low-MW peptides, oligosaccharides and monosaccharides. It was shown that soybean macromolecules are hydrolyzed to a large extent by fermentation with Bacillus spp., resulting in water-soluble low-MW compounds corresponding to the increase in TCA-soluble peptides and protein digestibility shown in Figure $1 \mathrm{~B}$ and $1 \mathrm{C}$. In addition, an increase in the amount of dialyzable matter of simulated digestion of F using gastrointestinal enzymes also clearly demonstrates the beneficial effect of Bacillus fermentation on food nutrient bioavailability in the stimulated digestion. Not only nitrogen content but also digestible material should be determined to confirm digestibility because TSN cannot represent amino acids and very short peptides. Thus, quantitative measurement of the short-chain peptides produced during simulated digestion performed using TCA-soluble peptides can be used to assess protein digestibility. The progress of hydrolysis was also confirmed by the determination of the TCA-soluble peptide content and is depicted in Figure 1B. Besides that, peptides have been reported more rapidly utilized than amino acids and proteins. ${ }^{15}$ It was shown that the progress of the digestion stage increased TCA-soluble peptides. The digested fraction of F showed the highest concentration of TCA-soluble peptides $(7.51-22.13 \mathrm{mg} / \mathrm{mL})$ followed by that in B (2.09-21.47 mg/mL) and S (0.64-9.07 mg/mL). The higher TCA-soluble peptide concentration $(7 \mathrm{mg} / \mathrm{mL}$ ) in $\mathrm{F}$ before simulated digestion (stage 0 ) is because of the large amount of soluble peptides initially present in $\mathrm{F}$ generated by $B$. subtilis fermentation. ${ }^{16}$ Then, during digestion, more TCA-soluble peptides were generated because of the reaction of digestive enzymes. Obviously, the TCA-soluble protein content for all kinds of soybean after simulated digestion (stage 4) was significantly higher than that before digestion (stage 
$0)(P<0.05)$. After the simulated gastric digestion stage, the increment of TCA in F, B and $S$

was 2.06-, 5.81- and 13.06-fold whereas the total increment after simulated digestion was 2.95-, 10.27- and 14.17-fold, respectively. From these numbers, it can be seen that a huge change was observed in the digested fraction of $\mathrm{B}$. Those results corresponded with the release of soluble nitrogen and free amino acid content and the increment of free amino acids by group, as reported in Figure $1 \mathrm{~A}$ and Tables 1 and 2, respectively. Increment of TCA-soluble peptides from the reaction of gastric enzymes in F was 2.06-fold and in B was 5.82-fold whilst it was 1.43-fold $(F)$ and 1.77-fold $(B)$ from the reaction of digestive enzymes in the simulated intestinal stage. From this, it can be inferred that protein digestion happens in the stomach stage more than the intestinal stage. The slight change of TCA-soluble peptides between before and after digestion in S can be understood by the presence of protease inhibitors especially trypsin inhibitor $(\mathrm{TI})$ which inhibits pancreatic protease, proteolysis and the absorption of dietary proteins. ${ }^{17} \mathrm{Chi}$ and $\mathrm{Cho}^{17}$ reported that the trypsin and a-chymotrypsin inhibitor content in raw soybean is $46 \pm 6 \mathrm{IU} / 10 \mathrm{~g}$ whereas that in natto is $2.7 \pm 1.6 \mathrm{IU} / 10 \mathrm{~g}$. Soybean meal contains $4.77 \mathrm{mg} / \mathrm{g}$ TI which decreases to $1.3 \mathrm{mg} / \mathrm{g}$ after heat treatment (by steaming at $100{ }^{\circ} \mathrm{C}$ for $30 \mathrm{~min}$ in an autoclave) Chi and Cho. ${ }^{17}$ Furthermore, some phenolic compounds present in soybeans are also known to inhibit protein absorption. This has been mainly explained by proteins being nonspecifically bound and precipitated by high concentrations of tannins which are therefore considered as antinutritional compounds. ${ }^{18}$ The change in TCA-soluble peptides between before and after simulated digestion showed that the protein in $B$ and $F$ was digested and protein utilization significantly improved. Chen et al. ${ }^{7}$ also reported augmentation of TCA-soluble peptides in fermented soybean compared to raw material or soybean flour. The increase in digestibility improves the nutritional quality of soybean proteins by favoring hydrolysis and the absorption of amino acids and short-chain peptides which are essential to human metabolism as can be seen from the amino acid compositions in Table 1.

132 Protein digestibility calculated from TCA-soluble peptides is shown in Figure 1C. Protein 
digestibility increased as the digestion stage progressed. $\mathrm{F}$ showed the highest protein digestibility (17.05-50.21\%) followed by B (4.75-48.71\%) and S (1.46-20.58\%) after the digestion. The rate of increment of protein digestibility, B showed a better increment (2.64fold) followed by $F(1.86$-fold) and $S$ (1.13-fold) compared to that of stage 1. Even though $B$ showed the highest protein digestibility increment rate, the protein digestibility of $F$ had a similar rate to that of B (around 1.2-fold) at the final digestion stage. The stable protein digestibility was observed in S from stage 1 until the end of the digestion. During simulated digestion, the protein in $\mathrm{F}$ and $\mathrm{B}$ was digested better than in $\mathrm{S}$. The increased in protein digestibility shows the ability of digestive enzymes in the simulated gastric digestion stage to digest the protein in $\mathrm{F}$ and $\mathrm{B}$. It could be assumed that both boiling and fermentation contributes to the improvement of protein digestibility. Digested F could improve oligopeptide fractions from bacterial fermentation, likewise as aid by heating thus improve protein digestibility. Moreover, the fermentation process results in a higher protein digestibility and available lysine content, especially when it is combined with microbial enzymes to significantly improve protein utilization. However, the slight difference between $\mathrm{F}$ and $\mathrm{B}$ could be explained by the effect of natto texture that has a slime-coated appearance which could hamper or delay the penetration of digestive enzymes. ${ }^{19}$ Besides, the presence of slime or mucilage could form sticky solutions or gels, and impact passage rate, stickiness as well as interactions with digestive enzymes and buffer solution in the stomach and small intestine. ${ }^{20,}$ 21.

\section{Soluble protein fractions and distribution by SDS-PAGE}

The soluble protein distribution profile at each stage of simulated digestion for $\mathrm{S}, \mathrm{B}$ and $\mathrm{F}$ is shown in Figure 2. Comparing So, the protein-based anti-nutrient factors, for example $\mathrm{TI}$ and allergens, were almost completely broken down and hydrolyzed into low-MW peptides in B0 and F0 due to the proteolysis that occurred during fermentation with Bacillus spp. var. natto. Besides that, the proteins $>28 \mathrm{kDa}$ were mostly eliminated, resulting in an accumulation of low-MW compounds as shown in Figure 2, F0, lane 13. Apart from the action of microbial 
enzymes by fermentation, Figure 2 shows a change in the distribution of proteins during simulated digestion. In B0-4 and F0-4, the high-MW proteins were obviously decreased, and the accumulation of small proteins was increased by the progress of the digestion stage. Our results showed that the ratio of the small protein fraction in stage 4 is the highest. During pepsin digestion stages (1-2), the intensity of the protein bands corresponding to $7 \mathrm{~S}$ and $11 \mathrm{~S}$ fractions was decreased and many peptide bands appeared at $<36 \mathrm{kDa}$, indicating protein hydrolysis (B1-B4). Simulated digestion of $\mathrm{F}$ caused complete degradation of polypeptides $>20 \mathrm{kDa}$ and increased the abundance of oligopeptides with $\mathrm{MW}<10 \mathrm{kDa}$ (F4, lane 17, Figure 2). Already after simulated digestion for $3 \mathrm{~h}(\mathrm{~F} 3$, lane 16), all protein subunits were degraded to a large extent, and after $4 \mathrm{~h}$ of simulated digestion virtually all big molecular-size proteins had disappeared (F4, lane 17). From the results, peptides with low MW were formed according to the degradation of some high MW peptides during simulated digestion. This result suggests that digestive enzymes containing active proteases decompose the larger proteins. In the case of pepsin hydrolysis, the subunits of fermented soybean protein were partially digested within $1-2 \mathrm{~h}$, whilst in intestinal digestion, most disappearance of larger molecules was found after $2 \mathrm{~h}$. Besides that, fermentation improves digestibility due to the reduction of the presence of anti-nutritional factors such as protease inhibitors (trypsin/chymotrypsin inhibitors), tannins and lectins and the degradation of soybean allergens by microbial proteolytic enzymes. ${ }^{3,22,23}$ This study verified that protein was mainly digested to smaller MW size fragments that could be a prime contributing factor to superior bioavailability and benefit to human health.

\section{Total phenolic content (TPC)}

Changes in TPC at each digestion stage of F, B and S are shown in Figure 3A. Overall, TPC escalated with the digestion stage progressed. Except in S, a remarkable increment was observed through the digested fractions of $F$ and $B$ at each digestion stage. The release of TPC into digested solution of $B(15.85-25.17 \mathrm{mg}$ GAE/g protein) was better than in F (10.41-25.65 mg GAE/g protein) whereas it was quite stable in S (10.58-14.00 mg GAE/g 
protein). This may be due to disruption of the cell matrix by heat, so soluble phenolics are released outside. In addition, digestive enzymes play a crucial role in exposing water-soluble polyphenols from the structure. Increments of 1.68- and 1.39-fold were found in F and B gastric fractions, respectively. Besides that, 1.47- and 1.13-fold increments were found between gastric and intestinal digestion for $F$ and $B$, respectively. Even though the amount of TPC in digested B was high, a bigger increment of TPC was observed in F. TPC in B and F was comparable in digestion stages 3 and 4 . This may correspond with the easier release of TPC in F than B. The structure between proteins and polyphenolics was broken by hydrolysis. During the gastric stage, more TPC leaching occurred than during intestinal stages. Pepsin could play a role in freeing TPC bound in the soybean structure. In addition, the increment in free phenolic acids in $F$ is probably due to the production of $\beta$-glucosidase during fermentation. ${ }^{24}$ An escalation in free phenolics is related to their antioxidant potential and expected to improve their bioavailability in the intestine.

Antioxidant activity. From Figure 3, it could be stated that there was more correlation between peptide content and antioxidant activity than between phenolic compound and antioxidant content, which means that the antioxidant activity of peptides is higher than that of phenolic compounds. All antioxidant properties improved between before and after digestion. F showed better DPPH, FRAP and MIC activity but not ABTS activity than B. The digested fraction of S showed higher DPPH activity than B; however, it was stable even when the digestion stage progressed. Besides that, the antioxidant activity of $\mathrm{S}$ was stable as the progress of the digestion. The digested fraction of $F$ showed the highest DPPH activity (24.12-68.00 $\mu \mathrm{mol}$ TE/g protein) followed by $S$ (40.03-51.52 $\mu \mathrm{mol}$ TE/g protein) and B (4.19-22.12 $\mu \mathrm{mol}$ TE/g protein) (Figure 3B). According to Yadav et al., ${ }^{25}$ a reduction in DPPH activity was observed in two of the studied cultivars (EC4216 and BL2) of cowpea seeds after thermal treatment as a result of leaching out of phenolic compounds from seeds due to heat application. Besides, phenolic compounds, especially tannins, are also likely to form insoluble complexes with protein of cowpea seed under some thermal conditions. ${ }^{25}$ 
This could explain the reduction of DPPH activity of B. However, F showed higher DPPH activity than $S$ and $B$, it may be because the activity of $S$ comes only from phenolic compound reactions not of both phenolic compounds and oligopeptides as in F. An increase in DPPH activity in F may corresponding to higher TPC content because microbial enzymes. Higher molecular weight phenolic compounds were depolymerized to simple phenolic monomers like catechins by metabolic activity of microbes. Additionally, fermentation can also change the level of bioactive compounds and can further breakdown cell walls of seed leading to liberation or synthesis of various bioactive compounds. ${ }^{26,27}$

The DPPH activity increased with the digestion stage progressed except that it was stable in $\mathrm{S}$. The increment of DPPH activity during gastric digestion was $2.42-$ and 1.96 -fold whereas that after the intestinal stage was 1.17- and 2.69-fold in F and B, respectively. Even though the DPPH activity in digested fractions of $F$ was higher than that of $B$, the big change in increment was found in B. The same trend as DPPH was observed for ABTS: the activity increased in the digestion stage progressed. ABTS ranged from 0.84 to $3.62,2.07$ to 2.99 and 0.97 to $1.08 \mathrm{mg} \mathrm{AA} / \mathrm{g}$ protein in $\mathrm{F}, \mathrm{B}$ and $\mathrm{S}$, respectively, as shown in Figure $3 \mathrm{C}$. The biggest change was found in $\mathrm{F}$ for the gastric stage $(2 \mathrm{~h})$ : ABTS increased $(P<0.05)$ approximately twice in the gastric stage (1.72 mg AA/g protein), followed by an increase of around 4.31-fold (3.62 $\mathrm{mg} \mathrm{AA} / \mathrm{g}$ protein) for the intestinal stage compared to the undigested stage $(0 \mathrm{~h})$ (0.84 mg AA/g protein). No big differences in ABTS were observed during digestion for B and S.

In the digested fractions of $F$, the biggest increment antioxidant activity was found in ABTS (4.32-fold) followed by DPPH (2.85-fold), MIC (2.21-fold) and FRAP (1.93-fold) compared to those in F0. Furthermore, FRAP of the digested fraction of F unceasingly accrued from 10.92 up to 18.80 and $21.10 \mu \mathrm{mol} \mathrm{FeSO}_{4} / \mathrm{g}$ protein for gastrointestinal and intestinal stage which calculated to almost 2-fold of increment $(P<0.05)$ whereas it increased slightly for B (9.96 to $18.95 \mu \mathrm{mol} \mathrm{FeSO}_{4} / \mathrm{g}$ protein) and was stable for $\mathrm{S}\left(7.13\right.$ to $9.22 \mu \mathrm{mol} \mathrm{FeSO}_{4} / \mathrm{g}$ protein) (Figure 3D). The augmentation in FRAP of digests shows that $F$ proteins can be 
more effective in donating electron after simulated digestion. The chelation of transition metals such as $\mathrm{Fe}^{2+}$ and $\mathrm{Cu}^{2+}$ helps to delay peroxidation and subsequently prevent food rancidity. The change of MIC activity during simulated digestion of $F, B$ and $S$ was also investigated (Figure 3E). For the digested fractions of $\mathrm{F}$, the MIC value was drastically increased from 2.76 to 5.47 and $6.10 \mu \mathrm{mol}$ EDTA/g protein for F0, F3 and F4, respectively $(P<0.05)$, which totally 2.2 -fold of increment. Surprisingly, the same increment in MIC was also found in $S$ ( 0.92 to $4.28 \mu \mathrm{mol} E D T A / g$ protein). A 2.13-fold increase was observed in the gastric stage, and a 2.00 -fold increment in the intestinal stage in S. In contrast, MIC was stable in B (1.73 to $2.18 \mu \mathrm{mol}$ EDTA/g protein) even though the phenolic compound content was higher. Soybeans can present significant values of phenolic compounds such as chlorogenic, gallic and protocatechuic acid. ${ }^{28}$ The metal-binding potency of phenolic compounds is dependent upon the number and location of hydroxyl groups, properly oriented functional groups and their unique phenolic structure as well as the presence of ortho-dihydroxy polyphenols. ${ }^{29}$ Even if a sample containing high polyphenols content, it might not show metal ion chelation activity because phenolic compounds can no longer bind metals once conjugated with a carbohydrate moiety, as in naturally occurring phenolic glycosides. ${ }^{26}$

Apart from phenolic compounds, antioxidant activity changes during simulated digestion, suggesting that generated bioactive peptides might play a main role. In the digestion, pepsin possibly disrupted the spatial structure of soybean peptides conducive to binding and trapping of metal ions and free radicals, resulting in reduced chelation and free-radical scavenging activity. In combination with, pancreatic digestion fully exposed or newly formed the high-affinity metal-binding groups including imidazole and carboxylic groups, thus ionic and electrostatic interactions with metal ions were likely imposed.

This study showed that antioxidant activity increased (in F) or was stable (in B) as the digestion stage progressed. The results distinctly stipulate that $F$ in the last stage of simulated digestion showed the highest activity. This may be due to short chain peptides 
convert free radicals into more stable products by donating electron atom to cease the radical chain reaction. ${ }^{30}$ From the results of higher antioxidant activity, $\mathrm{F}$ peptides were assumed to resist to the digestion condition and stay in the form with activity. Furthermore, another significant effecting factor in the overall antioxidant activity of hydrolyzed proteins is known to be the size of peptides. Moreover, factors including enzyme specificity, MW distribution, amino acid compositions and the specific sequences of the peptides released are shown to be largely effect antioxidant properties of peptides. ${ }^{30}$ Previous studies have reported that peptides with a lower MW (5-16 amino acids) have a higher probability of crossing the intestinal epithelium and exert better biological activity. ${ }^{31}$ Figure 2 shows the smaller peptides found in SDS-PAGE which may boost up antioxidant activity. In the study, in the final digest of $F(F 4)$ shows disappearance of larger MW peptides, however, exhibited the highest overall antioxidant capacity. This study proved that fermented soybeans show an improvement of antioxidant activity with the progress of the digestion stage and that generating antioxidant peptides tolerate digestive enzymes. This means it is possible for active peptides to reach the target site and show impressive reaction.

\section{Free amino acid composition}

The change of free amino acid profile was presented in terms of increment between before (stage 0) and after simulated digestion (stage 4) and is shown in Tables 1 and 2. When compared to $S$ before digestion (stage $0, B D$ ), the total increment of free amino acids in $S, B$ and F after digestion (stage 4 or G2I2) was 2.15-, 6.78- and 21.10-fold, respectively. The distinctive amino acids found in the soybeans were Ile, Glu, Val, Leu, Tyr, Phe, Lys and Asg (> $20 \mathrm{nmol} / \mathrm{mL}$ ). All other amino acid contents also increased; in particular, B4 and F4 showed the biggest increment (Table 1). When comparing between F0 and F4, most represented amino acids were increased significantly, around 1.5- to 3.5-fold. For F, the smallest change and the maximum changes were found in Pro (0.95-fold) and Arg (49.43fold), respectively, in F4. For B, there was a big difference in some amino acids between before and after digestion. There was drastic increase in Leu, Tyr, Phe, Lys and Arg, around 
Table 2 shows the change in content of free amino acids by different groups. The maximum change of 9.52-fold in B4 and 4.19-fold was observed in F4 in the essential amino acid (EAA) group. It can be assumed that the simulated digestion improves the generation of EAA as observed from the increment number (Table 2). We also found a remarkable increment in other groups of amino acids, for example, hydrophobic amino acids (HAA), aromatic amino acids (AAA) and antioxidant amino acids (AXA) of around 5.29- to 13.04-fold in cooked soybeans and 2.99- to 4.13-fold in F (Table 2). Peptide bonds between HAA and AAA such as Phe, Trp and Try are most effectively cleaved by pepsin. Pancreatin including trypsin (cleaved peptide bonds at Arg and Lys sites), chymotrypsin (cleaved peptide bonds at Phe, Trp, Tyr and Leu sites) and elastase (cleaved peptide bonds at Ala and other aliphatic amino acids). ${ }^{30}$ Figure 3 displayed that the notable increase in antioxidant properties is related the escalation in free amino acid content. The results for amino acid content in this study show the same trend with the increment of Glu, Val, Tyr, Leu and Phe in soybean meal fermented with $B$. subtilis. ${ }^{32}$ The free amino acid composition formed upon simulated digestion is widely referred to the antioxidant activity of a peptide. ${ }^{33,34}$ Thus, we inferred that the digested fractions of $F$ and $B$ which showed an increase of amino acids by simulated digestion could increase the nutritional value and physiological functions for humans.

\section{In vitro anti-inflammatory activity}

The digested soybeans fractions showed different trends in anti-inflammatory activity tested by NO production and egg albumin denaturation inhibition as shown in Figure 4A and 4B. For NO production inhibition, the inhibition activity increased with the progress of the digestion stage for all soybean conditions with the highest activity in B4 (31.68\%). Before digestion, inhibition of NO production activity progressively increased from $9.01 \%$ (F0) up to $28.54 \%(F 4)$. The same trends were found in $B(B 0-4)$ and $S(S 0-3)$ but a sharp decrease was found in S4 (10.32\%). From the results, the potential bioactivity of peptides released 
during stimulated digestion of fermented soybean proteins against inflammation is assumed. The inhibition of egg albumin denaturation was highest, at $95-98 \%$, in digested fractions of S (the protein concentration used of $1.25 \mathrm{mg} / \mathrm{mL}$ ). In $\mathrm{F}$, the values were quite stable (from $85.08 \%$ to $80.81 \%$ ) before and after gastric digestion (F1-F2), then decreased slightly (from $80.81 \%$ to $69.08 \%$ ) at the intestinal digestion stage (F3-4). For B, the inhibition reaction was increased in gastric stage fractions (from $73.0 \%$, B1 to $84.57 \%$, B2) then decreased slightly in the intestinal stage (from $84.57 \%$, B3 to $57.14 \%$, B4). This result proved that the resulting soybean peptides from simulated digestion were quite tolerant and could stabilize the inhibition of egg albumin denaturation. However, it is not only proteins that can play a role in anti-inflammatory action. Apart from proteins, saponins $(0.17-6.16 \%)$, phytic acid (1.0$2.2 \%)$, sterols $(0.23-0.46 \%)$, isoflavones $(0.1-0.3 \%)$ and lignans $(0.02 \%)$ sequentially present in soybean; they show a strong anti-inflammatory effect and display a wide range of other bioactivities, including antioxidative, anti-cancer, anti-viral, cardiovascular protective effects, and hepatoprotective actions. ${ }^{27}$ These interactive and complex effects should be considered in the further study.

\section{Conclusions}

Processing is important for both nutritional quality and the sensory of the product. Soaking and boiling are of important steps in the preparation for fermentation. However, how processing methods affect the health promoting phenolics and antioxidant activities have not been systematically studied especially when observed also under the in vitro digestion. Thus, this study found that uncooked soybean (Soaked, S) showed the lowest TPC, protein digestibility with stability in antioxidant activity but higher egg albumin degeneration inhibition activity with the digestion stage progressed. Boiling significantly affected TPC and antioxidant activity could be benefit to fermentation step. Fermented soybean $(F)$ showed the maximum TPC and antioxidant activity rather than S and cooked soybean (Boiled, B) could be attributed to the synergistic combinations of several types of factors including processing, 
metabolic activity of microbes and digestion. Cooked soybean (Boiled, B) and F had improved overall protein digestibility which means improved protein utilization as well as improved antioxidant properties after the digestion due to leaching out of bioactive compounds. Besides, the intense bioactivity in F generated from the accumulation of TPC and the concentration of peptides/free amino acids, low MW peptides as well as the high percentages of antioxidative amino acid residues. Processing not only improves flavor and palatability of but also increases protein utilization, bioavailability of nutrients and health benefits.

\section{Methods}

\section{Materials and reagents}

Soybeans (Glycine max cv. Enrei) were purchased from the market in Ibaraki prefecture, Japan and kept in a refrigerator $\left(4^{\circ} \mathrm{C}\right)$ before the experiment. Digestive enzymes for gastric digestion used porcine gastric mucosa pepsin (800-2500 U/mg protein; EC 3.4.23.1) and for intestinal digestion used porcine pancreas pancreatin (8 × USP specifications; EC 232-4689 ,), invertase from baker's yeast (grade VII, $\geq 300 / \mathrm{mg}$ solid) and amyloglucosidase (3260 $\mathrm{U} / \mathrm{mL}$ ), They were procured from Sigma-Aldrich Chemical Co. (St. Louis, MO, USA) and Megazyme International Ireland Ltd (Wicklow, Ireland). All other chemicals of analytical grade were purchased from Wako Pure Chemical Corporation (Tokyo, Japan).

\section{Sample preparation}

Soybean samples during fermentation process were collected after soaking (soaked soybeans "S"), boiling (boiled soybeans "B") and fermentation (fermented soybeans "F") following the method of Ketnawa and Ogawa. ${ }^{9}$ In summary, dehulled yellow-seeded soybean samples $(900$ g) were washed using tap water and soaked in distilled water (soybeans/water ratio of $1: 3, \mathrm{w} / \mathrm{v}$ ) for $18 \mathrm{~h}$ at $20^{\circ} \mathrm{C}$. Then, the soaked samples were separated from the soaking water. At this stage, part of the soaked samples was collected as soaked soybeans (S). Subsequently, soaked samples were washed again with tap water, 
boiled with the same ratio of fresh distilled water using a household pressure cooker $(\mathrm{H}-$ 5040, Pearl Metal Co., Ltd., Niigata, Japan) under approximately 100 kPa gauge pressure (approx. $120^{\circ} \mathrm{C}$ ) for $90 \mathrm{~min}$, and then cooled down at room temperature. At this stage, a part of the boiled samples was collected as boiled soybeans (B). Fermented soybeans were prepared according to Ketnawa and Ogawa. ${ }^{9}$ In summary, boiled soybeans (150 g) were transferred into a glass beaker and inoculated with $50 \mathrm{~mL}$ of the diluted culture of Bacillus spp. natto from a commercial natto product S-903 (Takanofoods Co., Ltd, Tokyo, Japan). After inoculation, the soybeans $(37.5 \mathrm{~g})$ were packed into a paper cup (205 $\mathrm{mL})$, the top surface covered with polyvinylidene chloride wrap film, and incubated at $40{ }^{\circ} \mathrm{C}$ for $18 \mathrm{~h}$. The products were collected and considered as fermented soybeans (F).

\section{Simulated in vitro gastrointestinal digestion}

The simulated static in vitro gastrointestinal digestion model described by Ketnawa and Ogawa $^{9}$ was used with minor adjustment and carried out in duplicate. Sampling of 5 sample sets was performed separately from each reactor. The sample was named as follows: 1) 0 or BD for samples before digestion, 2) 1 or $\mathrm{G} 1$ for samples from gastric digestion for $1 \mathrm{~h}, 3) 2$ or $\mathrm{G} 2$ for samples from gastric digestion for $2 \mathrm{~h}, 4) 3$ or $\mathrm{G} 2 \mathrm{l} 1$ for samples after gastric digestion for $2 \mathrm{~h}$ and intestinal digestion for $1 \mathrm{~h}$, and 5) 4 or G2I2 for samples after gastric digestion for $2 \mathrm{~h}$ and intestinal digestion for $2 \mathrm{~h}$ (after digestion). The following analyses were carried out in triplicate.

\section{Determination of total soluble nitrogen and protein content}

A CN coder (MT-700 Mark 2; Yanako, Tokyo, Japan) was employed to determine the total soluble nitrogen (TSN) content using method according to Ketnawa and Ogawa. ${ }^{9}$

\section{TCA-soluble peptide content}

TCA-soluble peptide content was analyzed following the method described by Chen et al. ${ }^{10}$ with minor modifications and described by Ketnawa and Ogawa. ${ }^{9}$ Digestibility was expressed as the percentage of TCA-soluble peptide content in the supernatant of the sample during digestion and after digestion compared to the total protein content of soaked 
soybeans. The protein digestibility was calculated using the following formula:

Protein digestibility $(\%)=B / A \times 100 \%$

where $A$ is the total protein content of soaked soybeans, and B is the TCA-soluble peptide content at each digestion stage.

\section{Soluble protein fractions and distribution by electrophoretic analysis}

Before studying protein patterns, Biuret method according to Gornall et al. ${ }^{11}$ using a standard bovine serum albumin (BSA) was employed for determination of the protein content of supernatants collected at different stages of simulated digestion in section 2.3. A sodium dodecyl sulfate polyacrylamide gel electrophoresis (SDS-PAGE) technique was applied to determine the protein patterns. The protein solution was diluted with deionized water to be the same concentration. The samples (all containing $20 \mu \mathrm{g}$ of protein per well) and the protein standard markers (Thermo Scientific, Rockford, IL, USA) were loaded onto NuPAGE ${ }^{\circledR}$ Bis-Tris gradient precast gel $\left(4 \sim 12 \%\right.$ gradient, $\left.10 \times 10 \mathrm{~cm}^{2}\right)$ in a Novex XCell Mini-Cell (Invitrogen, Thermo Scientific, Rockford, IL, USA) according to Ketnawa and Ogawa. ${ }^{9}$

\section{Free amino acid analysis}

An automatic amino acid analyzer (JLC-500/V2 equipped with an ion exchange column; Jeol, Tokyo, Japan) was used for determination of free amino acid content according to Ketnawa and Ogawa. ${ }^{9}$

\section{Biochemical properties}

Total phenolic content (TPC) and antioxidant activity determination such as scavenging activity on 2,2-diphenyl-1-picrylhydrazyl (DPPH), 2, 2'-azinobis-(3-ethylbenzothiazoline-6sulfonic acid) (ABTS) radical scavenging activities, reducing power activity on ferric (FRAP) and chelating metal ion activity (MIC) were determined using the method according to Ketnawa and Ogawa. ${ }^{9}$ In vitro anti-inflammatory activity such as nitric oxide (NO) inhibition activity and egg albumin protein denaturation were determined by method modified by Harsha et al. ${ }^{12}$ and Osman et al. ${ }^{13}$ respectively as previously described in Ketnawa and 
Ogawa. ${ }^{9}$

\section{Statistical analysis}

432 All determinations were carried out in triplicate. Statistical Package for the Social Sciences

433 (SPSS for Windows, SPSS, Inc., Chicago, IL) was employed using Duncan's multiple range 434 test for mean comparisons and analysis of variance. Differences were considered significant 435 at $P<0.05$.

\section{Ethical approval}

437 This article does not contain any studies with human participants or animals performed by 438 any of the authors.

\section{Acknowledgements}

440 Dr. Sunantha Ketnawa was awarded JSPS Postdoctoral Fellowship. Grateful thanks are extended to Dr. Tamaki Hirose, Research Facility Centre for Science and Technology, University of Tsukuba for technical support for free amino acid analysis and Assoc. Prof. Dr.

443 Terumasa Takahashi, Graduate School of Horticulture, Chiba University for crude protein 444 analysis.

\section{Author contribution}

S. K. designed the experiments, performed the experiments, data collection, analyzed data and wrote the manuscript. Y. O. supervised this study and reviewed the manuscript.

\section{Data availability}

449 The research data of this study will be provided upon request.

\section{Competing interests}

451 The authors declare no competing interests. The JSPS had no role in study design, data 452 collection, or analysis. The authors alone are responsible for the content and writing of the 453 paper.

454

\section{References}

456 1. Weng, Y.; Yao, J.; Sparks, S.; Wang, K. Y. Nattokinase: An oral antithrombotic agent for 
the prevention of cardiovascular disease. Int. J. Mol. Sci. 18 (3), 523-533. http:// doi:10.3390/ijms18030523 (2017).

2. Yang, Y.; Wang, Z.; Wang, R.; Sui, X.; Qi, B.; Han, F.; Jiang, L. Secondary structure and subunit composition of soy protein in vitro digested by pepsin and its relation with digestibility. Biomed. Res. Int. 2016 (1), 1-12, http://doi:10.1155/2016/5498639 (2016).

3. Frias, J.; Song, Y. S.; Martínez Villaluenga, C.; De Mejia, E. G.; Vidal Valverde, C.

4. Escamilla, D. M.; Rosso, M. L.; Holshouser, D. L.; Chen, P.; Zhang, B. Improvement of soybean cultivars for natto production through the selection of seed morphological and physiological characteristics and seed compositions: A review. Plant Breeding. 138 (2), 131-139. http://doi:10.1111/pbr.12678 (2019).

5. González Montoya, M.; Hernández Ledesma, B.; Mora Escobedo, R.; Martínez Villaluenga, C. Bioactive peptides from germinated soybean with anti-diabetic potential by inhibition of dipeptidyl peptidase-IV, a-amylase, and a-glucosidase enzymes. Int. J. Mol. Sci., 19 (10), 2883-2894, http://doi:10.3390/ijms19102883 (2018).

6. Weng, T. M.; Chen, M. T. Changes of protein in natto (a fermented soybean food) affected by fermenting time. Food Sci. Technol. Res. 16 (6), 537-542, http://doi:10.3136/fstr.16.537 (2010).

7. Chen, C. C.; Shih, Y. C.; Chiou, P. W. S.; Yu, B. Evaluating nutritional quality of single stage- and two stage-fermented soybean meal. Asian-Australas. J. Anim. Sci. 23 (5), 598-606, http://doi:10.5713/ajas.2010.90341 (2010).

8. Fujisawa, T.; Shinohara, K.; Kishimoto, Y.; Terada, A. Effect of miso soup containing Natto on the composition and metabolic activity of the human faecal flora. Micro. Eco.Health Disease. 18 (2), 79-84, http://doi:10.1080/08910600600931942 (2006).

9. Ketnawa, S.; Ogawa, Y. Evaluation of protein digestibility of fermented soybeans and changes in biochemical characteristics of digested fractions. J. Funct. Foods. 52, 640- 
647, https://doi.org/10.1016/j.jff.2018.11.046 (2019).

10. Chen, N.; Zhao, M.; Sun, W. Effect of protein oxidation on the in vitro digestibility of soy protein isolate. Food Chem. 141 (3), 3224-3229, https://doi.org/10.1016/j.foodchem.2013.05.113 (2013).

11. Gornall, A. G.; Bardawill, C. J.; David, M. M. Determination of serum proteins by means of the biuret reaction. J. Biol. Chem. 177 (2), 751-766, http://doi: 10.1159/000219790 (1949).

12. Harsha, S. N.; Anilakumar, K. R.; Mithila, M. V. Antioxidant properties of Lactuca sativa leaf extract involved in the protection of biomolecules. Biomed. Prev. Nutr. 3 (4), 367373, https://doi.org/10.1016/j.bionut.2013.06.003 (2013).

13. Osman, N. I.; Sidik, N. J.; Awal, A.; Adam, N. A. M.; Rezali, N. I. In vitro xanthine oxidase and albumin denaturation inhibition assay of Barringtonia racemosa L. and total phenolic content analysis for potential anti-inflammatory use in gouty arthritis. $J$. Intercult. Ethnopharmacol. 5 (4), 343-349, http://doi:10.5455/jice.20160731025522 (2016).

14. Lee, J. H.; Kim, B.; Hwang, C. E.; Haque, M. A.; Kim, S. C.; Lee, C. S.; Lee, D. H. Changes in conjugated linoleic acid and isoflavone contents from fermented soymilks using Lactobacillus plantarum P1201 and screening for their digestive enzyme inhibition and antioxidant properties. J. Funct. Foods. 43, 17-28, https://doi.org/10.1016/j.jff.2018.01.022 (2018).

15. Kodera, T.; Hara, H.; Nishimori, Y.; Nio, N. Amino acid absorption in portal blood after duodenal infusions of a soy protein hydrolysate prepared by a novel soybean protease D3. J. Food Sci. 71 (7), 517-525, https://doi.org/10.1111/j.1750-3841.2006.00118.x (2006).

16. Kiers, J. L.; Van laeken, A. E. A.; Rombouts, F. M.; Nout, M. J. R. In vitro digestibility of Bacillus fermented soya bean. Int. J. Food Microbiol. 60 (2), 163-169, https://doi.org/10.1016/S0168-1605(00)00308-1 (2000). 
17. Chi, C. H.; Cho, S. J. Improvement of bioactivity of soybean meal by solid-state fermentation with Bacillus amyloliquefaciens versus Lactobacillus spp. and Saccharomyces cerevisiae. LWT-Food Sci. Tech. 68, 619-625, https://doi.org/10.1016/j.Iwt.2015.12.002 (2016).

18. Martinez-Gonzalez, A. I.; Díaz-Sánchez, Á. G.; de al Rosa, L. A.; Vargas-Requena, C. L.; Bustos-Jaimes, I.; Alvarez-Parrilla, E. Polyphenolic compounds and digestive enzymes: In vitro non-covalent interactions. Molecules, 22 (4), 669-684, doi:10.3390/molecules22040669 (2017).

19. Hu, Y.; Ge, C.; Yuan, W.; Zhu, R.; Zhang, W.; Du, L.; Xue, J. Characterization of fermented black soybean natto inoculated with Bacillus natto during fermentation. J. Sci. Food Agric. 90 (7), 1194-1202, http://doi:10.1002/jsfa.3947 (2010).

20. Fiszman, S.; Varela, P. The role of gums in satiety/satiation. A review. Food Hydrocoll. 32 (1), 147-154, https://doi.org/10.1016/j.foodhyd.2012.12.010 (2013).

21. Xu, K.; Guo, M.; Roman, L.; Pico, J.; Martinez, M. M. Okra seed and seedless pod: Comparative study of their phenolics and carbohydrate fractions and their impact on bread-making. Food Chem. 317, 126387-126398, https://doi.org/10.1016/j.foodchem.2020.126387 (2020).

22. Aguirre, L.; Garro, M. S.; Savoy de Giori, G. Enzymatic hydrolysis of soybean protein using lactic acid bacteria. Food Chem. 111 (4), 976-982, https://doi.org/10.1016/j.foodchem.2008.05.018 (2008).

23. Wang, T.; Qin, G. X.; Sun, Z. W.; Zhao, Y. Advances of research on glycinin and $\beta-$ conglycinin: a review of two major soybean allergenic proteins. Crit. Rev. Food Sci. Nutr. 54 (7), 850-862, http://doi: 10.1080/10408398.2011.613534 (2014).

24. Bhanja, T.; Kumari, A.; Banerjee, R. Enrichment of phenolics and free radical scavenging property of wheat koji prepared with two filamentous fungi. Bioresour. Technol. 100 (11), 2861-2866, https://doi.org/10.1016/j.biortech.2008.12.055 (2009). 25. Yadav, N.; Kaur, D.; Malaviya, R.; Singh, M.; Fatima, M.; Singh, L. Effect of thermal and 

non-thermal processing on antioxidant potential of cowpea seeds. Int. J. Food Prop. 21 (1), 437-451, https://doi.org/10.1080/10942912.2018.1431659 (2018).

26. Moktan, B.; Saha, J.; Sarkar, P. K. Antioxidant activities of soybean as affected by Bacillus-fermentation to kinema. Food Res. Int. 41 (6), 586-593, https://doi.org/10.1016/j.foodres.2008.04.003 (2008).

27. Sanjukta, S.; Rai, A. K. Production of bioactive peptides during soybean fermentation and their potential health benefits. Trends Food Sci. Technol. 50, 1-10, https://doi.org/10.1016/j.tifs.2016.01.010 (2016).

28. Silva, M. O.; Brigide, P.; de Toledo, N. M. V.; Canniatti-Brazaca, S. G. Phenolic compounds and antioxidant activity of two bean cultivars (Phaseolus vulgaris L.) submitted to cooking. Brazilian J. Food Technol.21, 2016072-2016083, http://dx.doi.org/10.1590/1981-6723.7216 (2018).

29. Andjelković, M.; van Camp, J.; de Meulenaer, B.; Depaemelaere, G.; Socaciu, C.; Verloo, M.; Verhe, R. Iron-chelation properties of phenolic acids bearing catechol and galloyl groups. Food Chem. 98 (1), 23-31, https://doi.org/10.1016/j.foodchem.2005.05.044 (2006).

30. Aluko, R. E. Amino acids, peptides, and proteins as antioxidants for food preservation. In Handbook of Antioxidants for Food Preservation; Shahidi, F., Ed.; Woodhead Publishing: Cambridge, UK, 105-140 (2015).

31. Ketnawa, S.; Martínez-Alvarez, O.; Benjakul, S.; Rawdkuen, S. Gelatin hydrolysates from farmed Giant catfish skin using alkaline proteases and its antioxidative function of simulated gastro-intestinal digestion. Food Chem. 192, 34-42, https://doi.org/10.1016/j.foodchem.2015.06.087 (2016).

32. Song, Y. S.; Frias, J.; Martinez-Villaluenga, C.; Vidal-Valdeverde, C.; de Mejia, E.G. Immunoreactivity reduction of soybean meal by fermentation, effect on amino acid composition and antigenicity of commercial soy products. Food Chem. 108 (2), 571-581, https://doi.org/10.1016/j.foodchem.2007.11.013 (2008). 
565 33. Ajibola, C. F.; Fashakin, J. B.; Fagbemi, T. N.; Aluko, R. E. Effect of peptide size on antioxidant properties of african yam bean seed (Sphenostylis stenocarpa) protein hydrolysate fractions. Int. J. Mol. Sci. 12 (10), 6685-6702, http://doi:

568 10.3390/ijms12106685 (2011).

569 34. Sánchez, A.; Vázquez, A. Bioactive peptides: A review. Food Qual. Safe. 1 (1), 29-46, http://doi:10.1093/fqsafe/fyx006 (2017). 
571 Table 1. Changes in free amino acid content in soaked, boiled and fermented soybeans

572 during simulated in vitro gastrointestinal digestion.

\begin{tabular}{|c|c|c|c|c|c|c|}
\hline \multirow{2}{*}{$\begin{array}{l}\text { Amino } \\
\text { acids }^{*}\end{array}$} & \multicolumn{2}{|c|}{ 'S', Soaked bean } & \multicolumn{2}{|c|}{ 'B', Boiled bean } & \multicolumn{2}{|c|}{ 'F', Fermented bean } \\
\hline & $\begin{array}{c}\text { BD } \\
(\text { Stage 0) }\end{array}$ & $\begin{array}{c}\text { G212 } \\
\text { (Stage 4) }\end{array}$ & $\begin{array}{c}\text { BD } \\
(\text { Stage } 0) \\
\end{array}$ & $\begin{array}{c}\text { G2I2 } \\
\text { (Stage 4) } \\
\end{array}$ & $\begin{array}{c}\text { BD } \\
(\text { Stage } 0) \\
\end{array}$ & $\begin{array}{c}\text { G2I2 } \\
\text { (Stage 4) } \\
\end{array}$ \\
\hline Thr & $0.58 \pm 0.05$ & $0.73 \pm 0.05$ & $0.00 \pm 0.00$ & $2.49 \pm 0.04$ & $1.93 \pm 0.02$ & $4.65 \pm 0.06$ \\
\hline Ser & $0.87 \pm 0.05$ & $1.10 \pm 0.05$ & $0.00 \pm 0.00$ & $2.94 \pm 0.04$ & $3.13 \pm 0.03$ & $6.65 \pm 0.06$ \\
\hline Asp & $1.12 \pm 0.09$ & $0.89 \pm 0.00$ & $0.00 \pm 0.00$ & $3.90 \pm 0.01$ & $3.45 \pm 0.03$ & $8.01 \pm 0.73$ \\
\hline Glu & $4.37 \pm 0.07$ & $3.16 \pm 0.01$ & $0.00 \pm 0.00$ & $4.33 \pm 0.03$ & $26.66 \pm 0.26$ & $44.38 \pm 0.24$ \\
\hline Gly & $0.58 \pm 0.08$ & $1.18 \pm 0.07$ & $0.00 \pm 0.00$ & $2.41 \pm 0.06$ & $5.17 \pm 0.46$ & $8.83 \pm 0.95$ \\
\hline Ala & $3.35 \pm 0.03$ & $2.29 \pm 0.13$ & $11.91 \pm 0.95$ & $11.00 \pm 0.85$ & $6.77 \pm 0.68$ & $12.35 \pm 0.34$ \\
\hline Val & $5.58 \pm 0.02$ & $5.69 \pm 0.09$ & $5.09 \pm 0.36$ & $9.65 \pm 0.55$ & $14.57 \pm 0.67$ & $26.70 \pm 0.27$ \\
\hline Met & $0.62 \pm 0.02$ & $1.05 \pm 0.02$ & $0.00 \pm 0.00$ & $2.79 \pm 0.06$ & $6.46 \pm 0.74$ & $15.05 \pm 0.61$ \\
\hline Cysta** & $1.96 \pm 0.03$ & $3.01 \pm 0.06$ & $1.98 \pm 0.14$ & $3.36 \pm 0.09$ & $4.78 \pm 0.08$ & $8.92 \pm 0.54$ \\
\hline Ile & $0.57 \pm 0.01$ & $1.74 \pm 0.02$ & $0.00 \pm 0.00$ & $3.91 \pm 0.07$ & $9.18 \pm 0.90$ & $20.93 \pm 0.31$ \\
\hline Leu & $0.63 \pm 0.06$ & $14.22 \pm 0.26$ & $0.00 \pm 0.00$ & $28.21 \pm 0.45$ & $24.98 \pm 0.79$ & $91.09 \pm 0.82$ \\
\hline Tyr & $1.03 \pm 0.07$ & $8.01 \pm 0.09$ & $1.51 \pm 0.14$ & $25.68 \pm 0.43$ & $22.22 \pm 0.23$ & $86.40 \pm 0.67$ \\
\hline Phe & $0.99 \pm 0.05$ & $15.58 \pm 0.01$ & $2.49 \pm 0.20$ & $41.73 \pm 0.27$ & $37.45 \pm 0.53$ & $123.78 \pm 0.36$ \\
\hline His & $1.75 \pm 0.12$ & $1.65 \pm 0.01$ & $1.91 \pm 0.03$ & $4.07 \pm 0.80$ & $11.87 \pm 0.36$ & $18.87 \pm 0.99$ \\
\hline Lys & $1.84 \pm 0.13$ & $3.81 \pm 0.03$ & $1.93 \pm 0.05$ & $18.48 \pm 0.40$ & $34.04 \pm 0.35$ & $133.58 \pm 0.57$ \\
\hline Trp & $\mathrm{n} / \mathrm{a}$ & $\mathrm{n} / \mathrm{a}$ & $\mathrm{n} / \mathrm{a}$ & $\mathrm{n} / \mathrm{a}$ & $\mathrm{n} / \mathrm{a}$ & $\mathrm{n} / \mathrm{a}$ \\
\hline Arg & $10.80 \pm 0.01$ & $14.61 \pm 0.08$ & $14.90 \pm 1.10$ & $83.16 \pm 0.14$ & $3.23 \pm 0.20$ & $160.19 \pm 0.99$ \\
\hline Pro & $0.00 \pm 0.00$ & $0.00 \pm 0.00$ & $0.00 \pm 0.00$ & $0.00 \pm 0.00$ & $2.56 \pm 0.00$ & $2.46 \pm 0.00$ \\
\hline Total & $36.62 \pm 0.89$ & $78.73 \pm 1.96$ & $41.72 \pm 2.97$ & $248.11 \pm 4.29$ & $218.45 \pm 6.33$ & $772.86 \pm 8.47$ \\
\hline
\end{tabular}

$573{ }^{*}$ Free amino acids are expressed by the quantity $(\mathrm{nmol} / \mathrm{mL})$ of each individual amino acid.

574 Each value represents the mean of three replications \pm standard deviation. Means in a

575 column with a different letter are significantly different $(P<0.05)$. Different capital letters in

576 the same column indicate a significant difference $(P<0.05)$ among the same conditions of

577 digestion.

$578{ }^{* *}$ Cysteine (Cys) is determined in the form of cystathionine (Cysta). Cysta is a dipeptide

579 formed by serine and homocysteine; the trans-sulfuration of methionine yields homocysteine

580 which combines with serine to form cystathionine. Tryptophan (Trp) cannot be reported

581 because it is unstable and produces ammonia, so it was not obtained in the amino acid

582 standard solution (values are means of duplicate measurements). 
Table 2. Increment of specific amino acid groups of boiled and fermented beans compared

584 to soaked bean and changes between before and after simulated digestion.

\begin{tabular}{|c|c|c|c|c|}
\hline $\begin{array}{c}\text { Amino acid } \\
\text { group* }\end{array}$ & \multicolumn{2}{|c|}{$\begin{array}{c}\text { Increment (fold)** } \\
\text { compared to soaked bean }\end{array}$} & \multicolumn{2}{c|}{$\begin{array}{c}\text { Increment (fold) } \\
\text { between digestion }\end{array}$} \\
\hline & 'B', Boiled bean & 'F', Fermented bean & 'B', Boiled bean & 'F', Fermented bean \\
\hline EAA & $112.29 \pm 13.23$ & $269.61 \pm 27.83$ & $9.52 \pm 1.34$ & $4.13 \pm 0.47 \mathrm{a}$ \\
\hline HAA & $97.40 \pm 11.15$ & $218.76 \pm 25.04$ & $5.29 \pm 0.78$ & $3.01 \pm 0.33 \mathrm{~b}$ \\
\hline AAA & $45.22 \pm 2.79$ & $35.72 \pm 5.27$ & $13.04 \pm 1.43$ & $3.20 \pm 0.35 \mathrm{~b}$ \\
\hline AXA & $32.29 \pm 1.41$ & $8.91 \pm 1.51$ & $6.93 \pm 0.99$ & $2.99 \pm 0.32 \mathrm{~b}$ \\
\hline
\end{tabular}

$585{ }^{\star}$ EAA = essential amino acids: Arg, His, Ile, Leu, Lys, Met, Phe, Thr, Try and Val;

586 HAA = hydrophobic amino acids: Ala, Val, lle, Leu, Tyr, Phe, Trp, Pro, Met and Cys;

587 AAA = aromatic amino acids: Phe, Trp, Tyr and His; AXA = antioxidant amino acids: Trp, Tyr,

588 Met, Cys, His, Phe and Pro.

$589^{* *}$ The increment of amino acids was calculated by dividing the quantity $(\mathrm{nmol} / \mathrm{mL})$ of each

590 individual amino acid by that of raw soybeans before digestion (SO) and itself before and

591 after digestion. The values are expressed as fold-changes of increment (values are means

592 of duplicate measurements). Different capital letters in the same column indicate a

593 significant difference $(P<0.05)$ among different amino acid groups. 
595 Figure 1. Change in total soluble nitrogen content (A), trichloroacetic acid (TCA)-soluble peptides (B), and protein digestibility $(C)$ of soaked, boiled, and fermented soybeans at each digestion stage. Bars represent the standard deviation from triplicate determinations. Different lowercase and uppercase letters indicate significant differences $(P<0.05)$ among mean values among digestion stages and those among samples, respectively.

Figure 2. Changes in SDS-PAGE electrophoretogram for soaked, boiled and fermented soybean protein at each digestion stage. Lanes 1 and 12 represent a standard molecular marker (MK); lanes 2-6 present soaked bean before digestion (S0), gastric digestion $1 \mathrm{~h}$ (S1), gastric digestion $2 \mathrm{~h}(\mathrm{~S} 2)$, intestinal digestion $1 \mathrm{~h}$ after gastric digestion (S3) and intestinal digestion $2 \mathrm{~h}$ after gastric digestion (S4), respectively; lanes 7-11 are for boiled bean in the same simulated digestion (B0-B4); lanes 13-17 are for fermented bean in the same simulated digestion (F0-F4).

Figure 3. Total phenolic content (TPC) expressed as mg of gallic acid equivalents / g protein equivalents / g protein (D) and metal ion chelating activity (MIC) expressed as $\mu$ mol EDTA equivalents / g protein (E) of soaked, boiled, and fermented soybeans at each digestion stage. Bars represent the standard deviation from triplicate determinations. Non-significant differences are highlighted with an asterisk $(P>0.05)$. Different lowercase and uppercase letters indicate significant differences $(P<0.05)$ among mean values among digestion phases and those among samples, respectively.

Figure 4. Anti-inflammatory activity by inhibiting nitric oxide production and egg albumin protein denaturation of each condition of soaked, boiled, and fermented soybeans at each digestion stage, reported as percentages. Different lowercase and uppercase letters indicate significant differences $(P<0.05)$ among mean values among digestion phases and those 
621 among samples, respectively. 

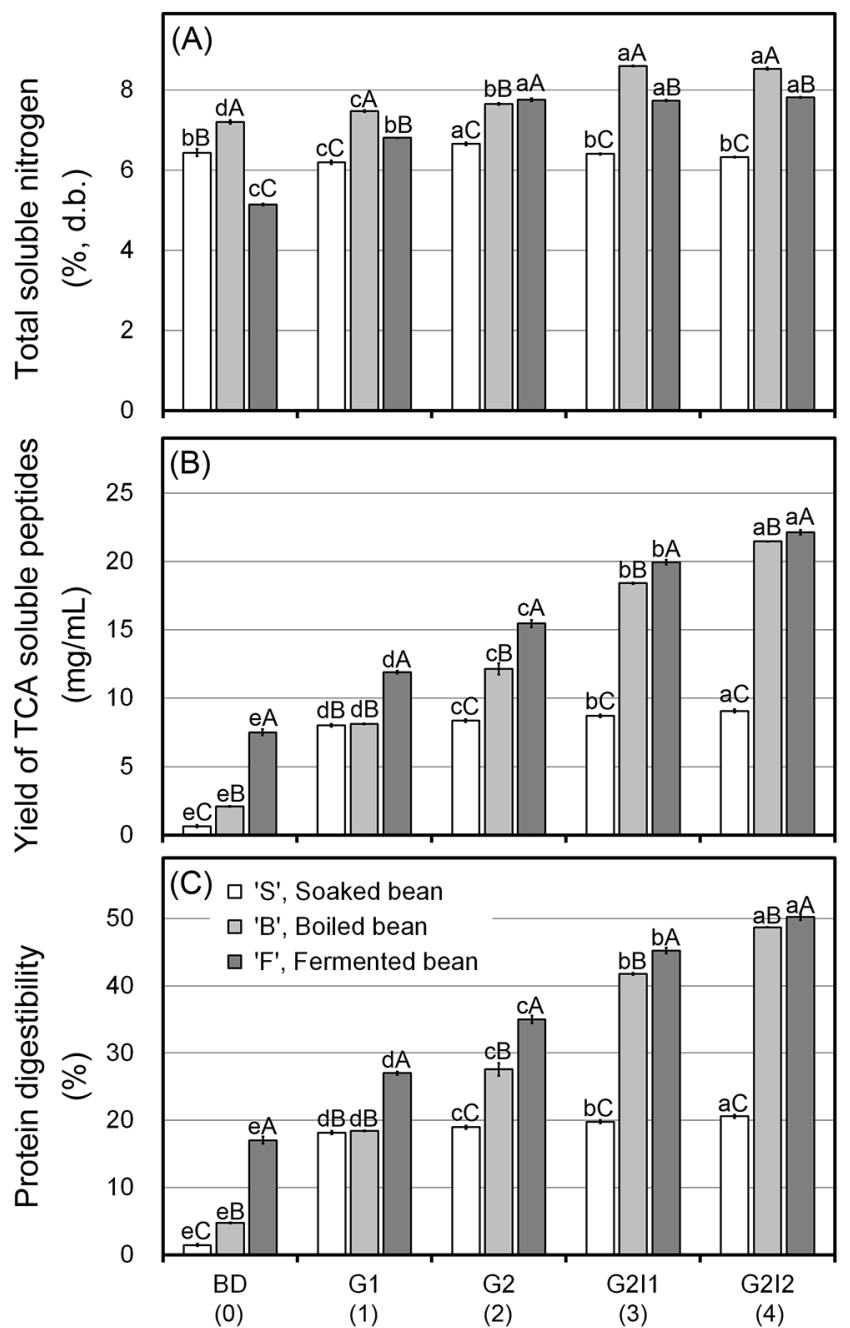

622

Simulated gastrointestinal digestion stage

\section{Figure 1}

624 


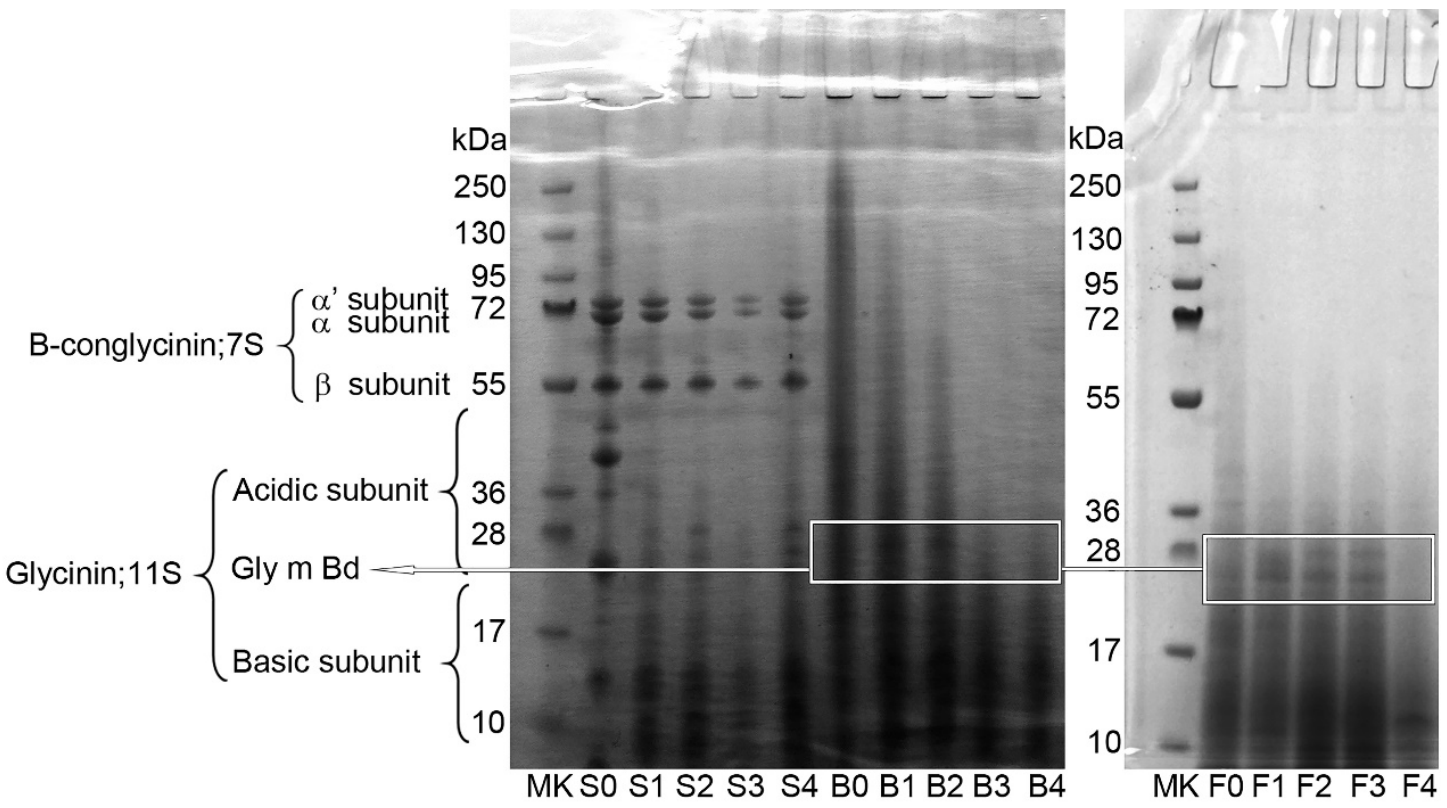

626 Figure 2 

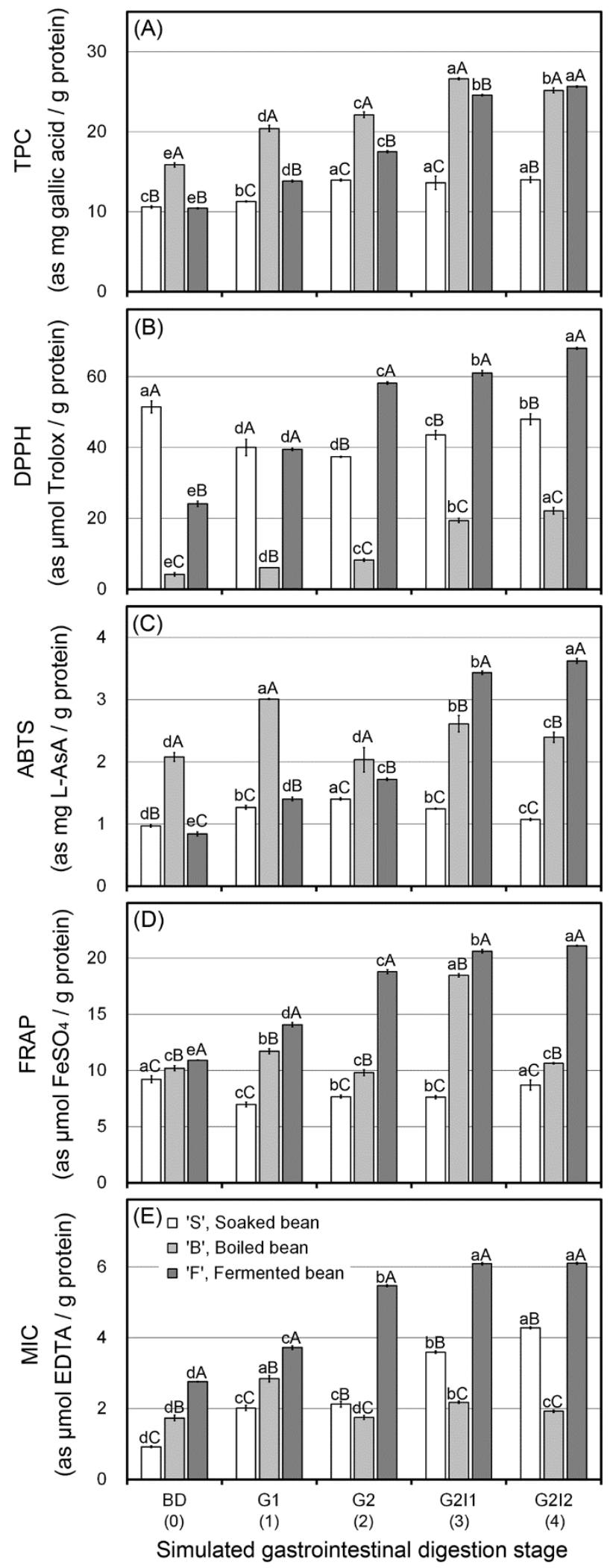

Figure 3 

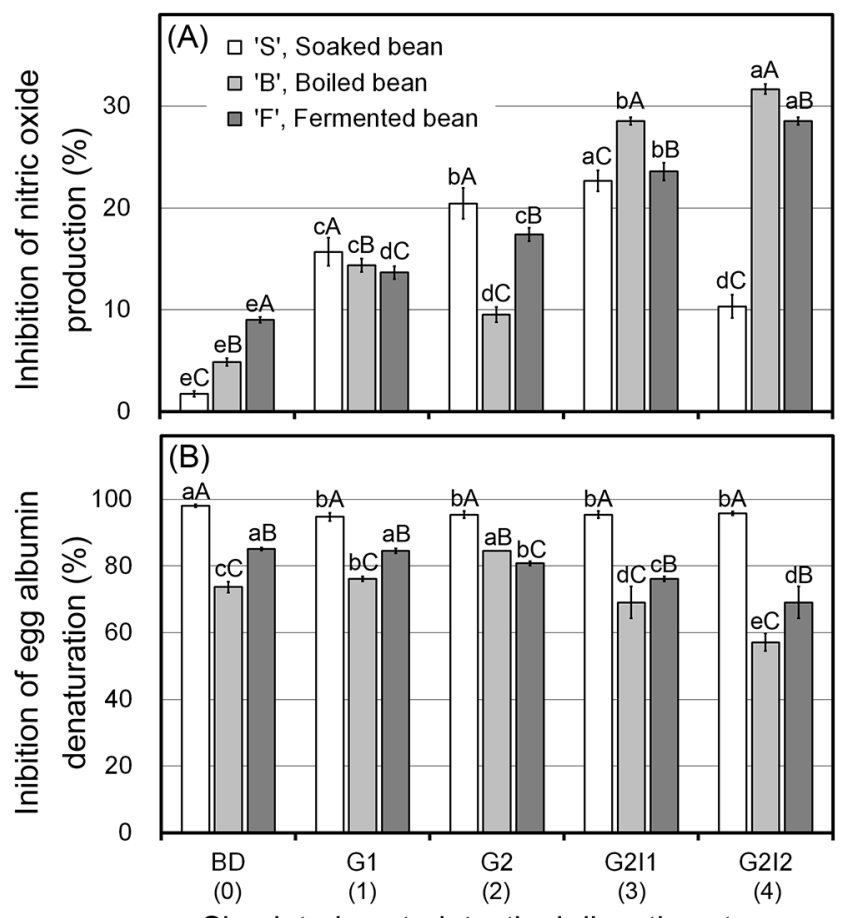

Simulated gastrointestinal digestion stage

Figure 4 
Figures
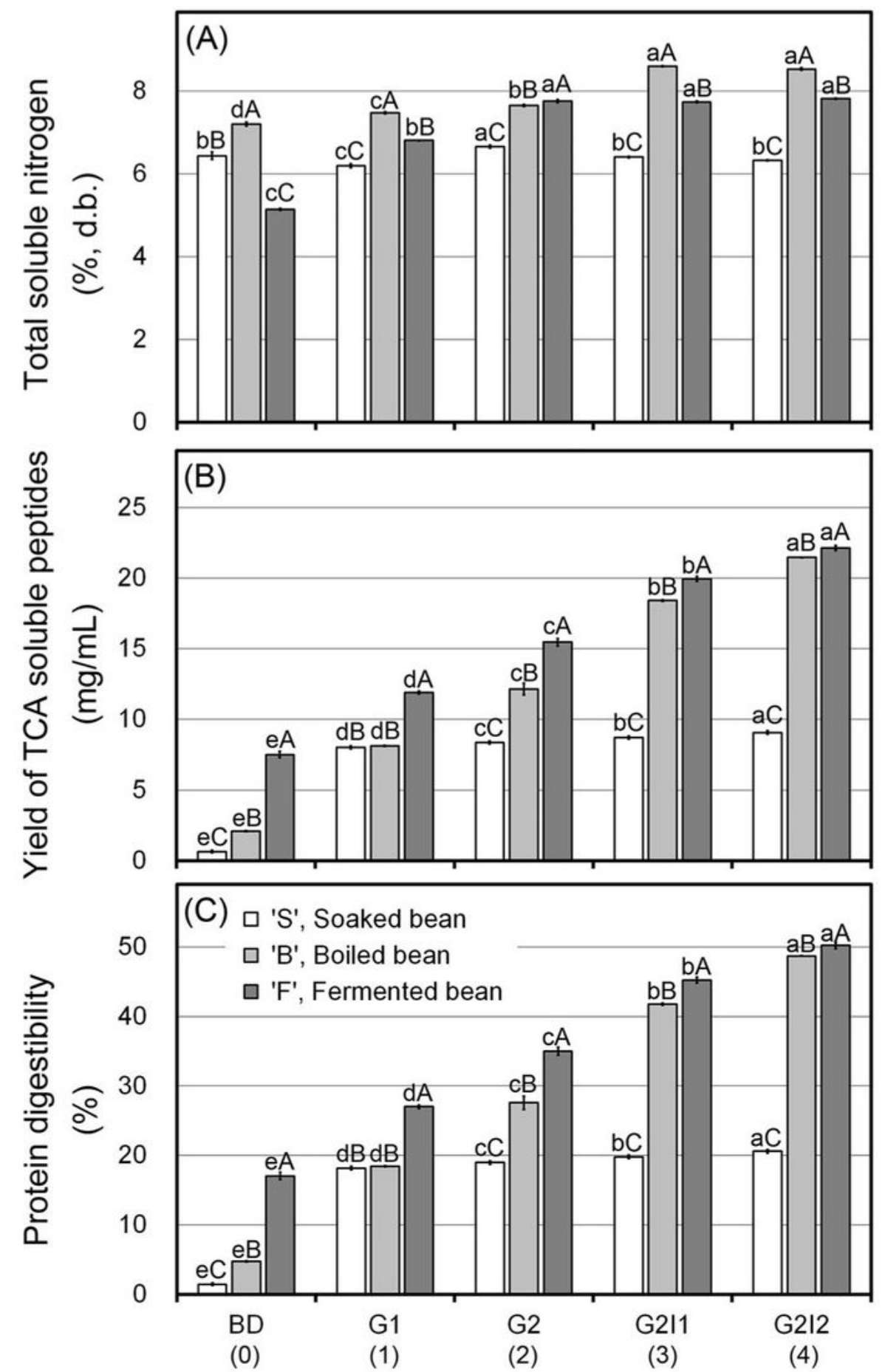

Simulated gastrointestinal digestion stage

\section{Figure 1}

Change in total soluble nitrogen content $(A)$, trichloroacetic acid (TCA)-soluble peptides (B), and protein digestibility (C) of soaked, boiled, and fermented soybeans at each digestion stage. Bars represent the standard deviation from triplicate determinations. Different lowercase and uppercase letters indicate 
significant differences $(P<0.05)$ among mean values among digestion stages and those among samples, respectively.

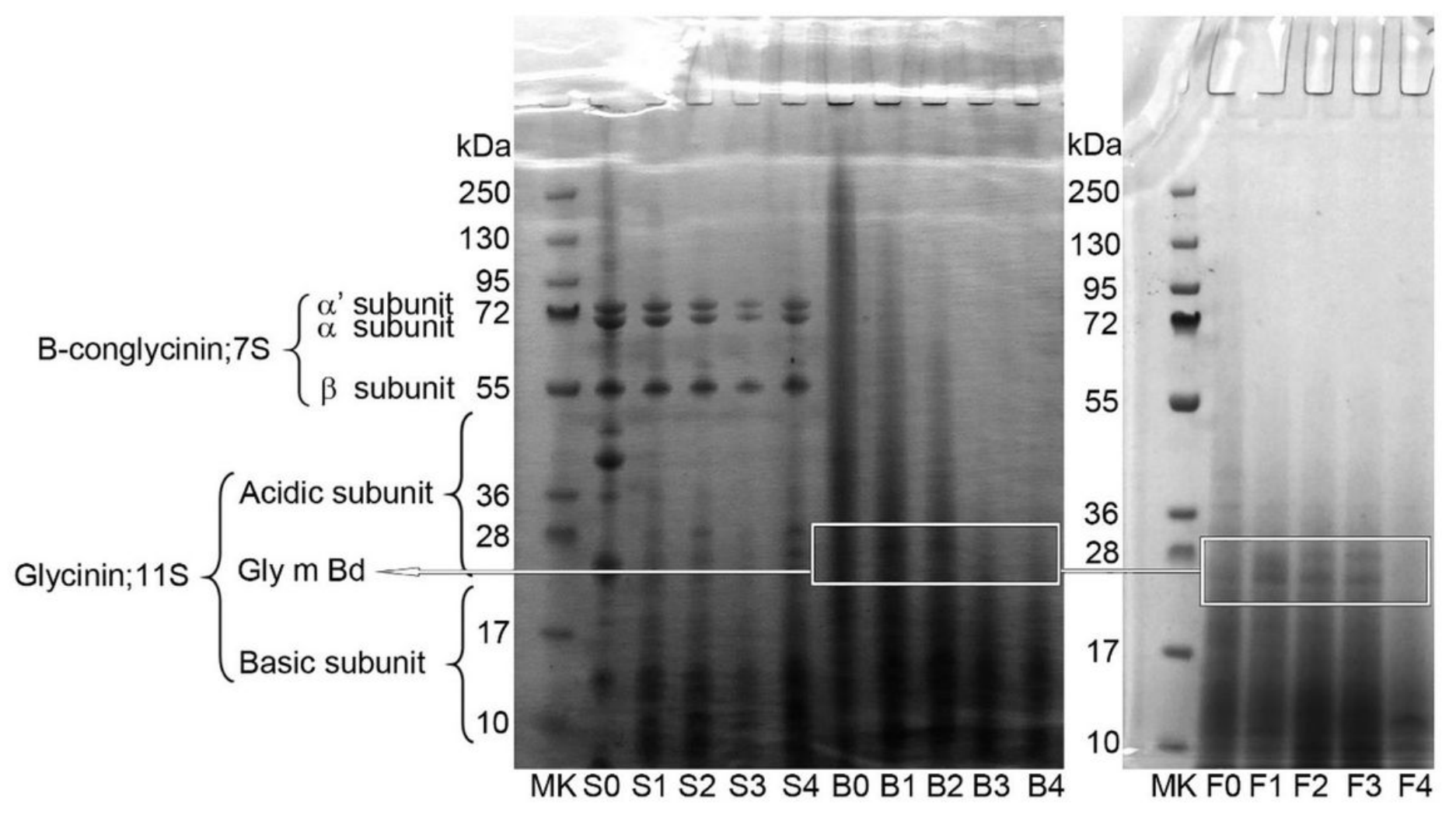

\section{Figure 2}

Changes in SDS-PAGE electrophoretogram for soaked, boiled and fermented soybean protein at each digestion stage. Lanes 1 and 12 represent a standard molecular marker (MK); lanes 2-6 present soaked bean before digestion (S0), gastric digestion $1 \mathrm{~h}$ (S1), gastric digestion $2 \mathrm{~h}$ (S2), intestinal digestion $1 \mathrm{~h}$ after gastric digestion (S3) and intestinal digestion $2 \mathrm{~h}$ after gastric digestion (S4), respectively; lanes 711 are for boiled bean in the same simulated digestion (B0-B4); lanes 13-17 are for fermented bean in the same simulated digestion (F0-F4). 

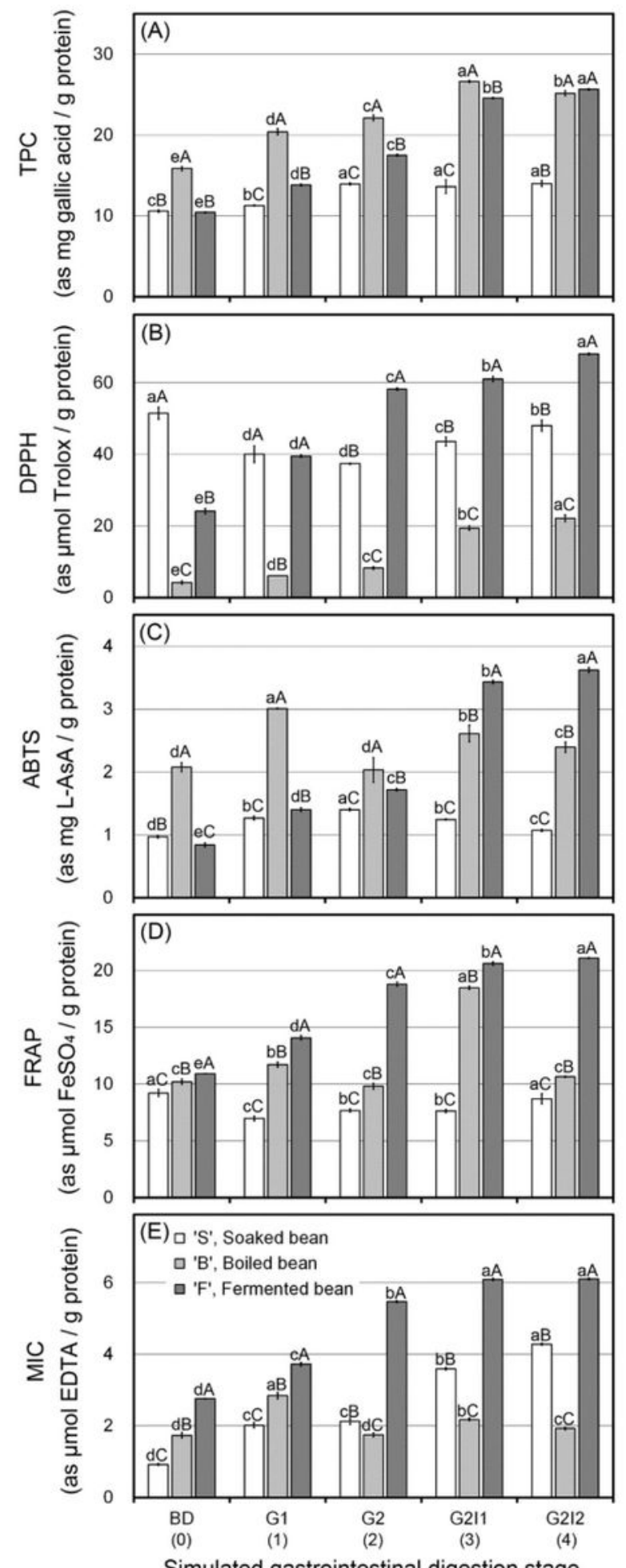

\section{Figure 3}

Total phenolic content (TPC) expressed as mg of gallic acid equivalents / g protein (A), DPPH radical scavenging capacity (DPPH) expressed as $\mu \mathrm{mol}$ Trolox equivalents / g protein (B), ABTS radical scavenging capacity (ABTS) expressed as $\mathrm{mg}$ of ascorbic acid equivalents / g protein (C), ferric reducing ability (FRAP) expressed as mmol FeSO4.7H2O equivalents / g protein (D) and metal ion chelating activity (MIC) expressed as $\mu$ mol EDTA equivalents / g protein (E) of soaked, boiled, and fermented 
soybeans at each digestion stage. Bars represent the standard deviation from triplicate determinations. Non-significant differences are highlighted with an asterisk $(P>0.05)$. Different lowercase and uppercase letters indicate significant differences $(P<0.05)$ among mean values among digestion phases and those among samples, respectively.
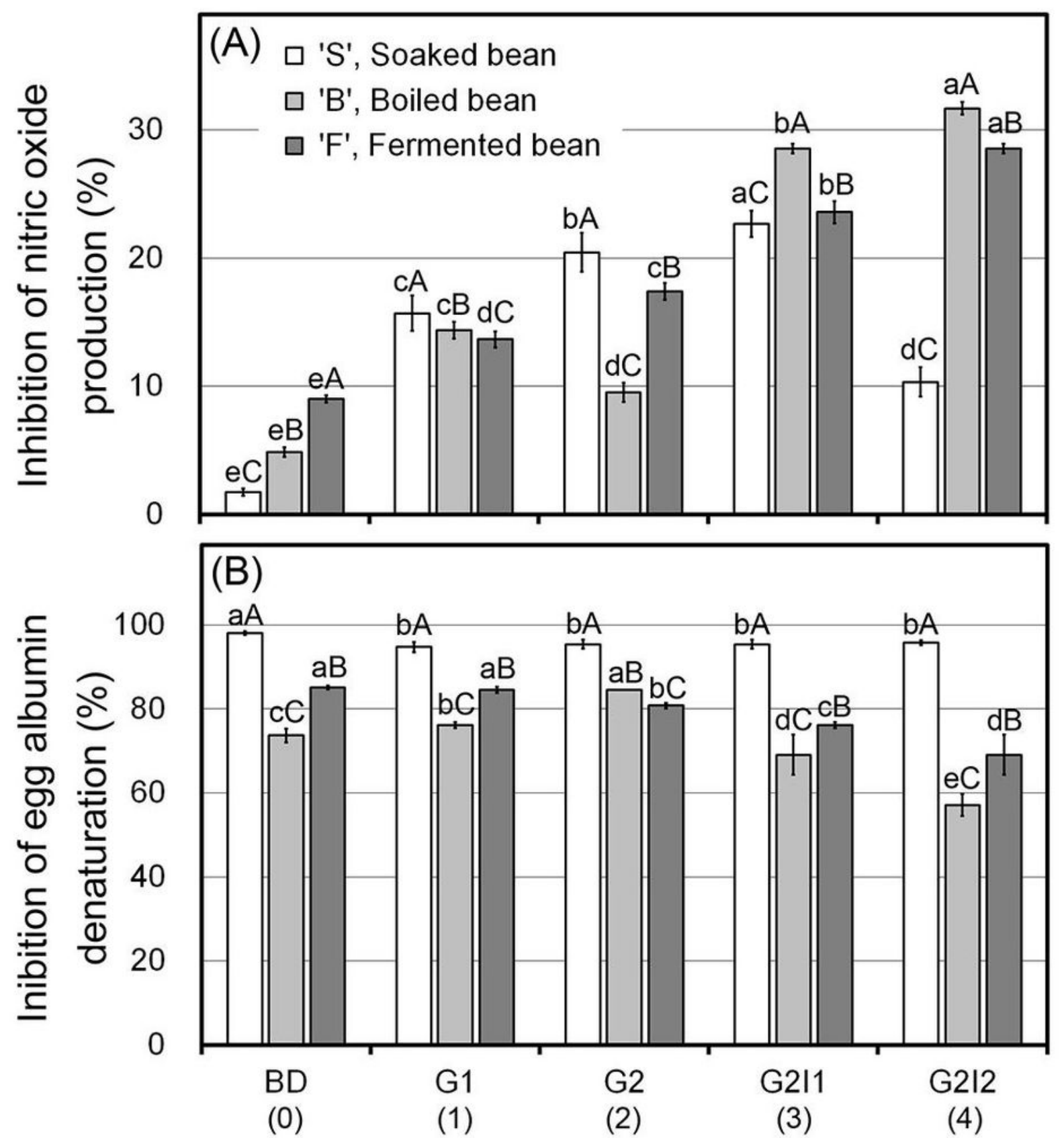

Simulated gastrointestinal digestion stage

Figure 4 
Anti-inflammatory activity by inhibiting nitric oxide production and egg albumin protein denaturation of each condition of soaked, boiled, and fermented soybeans at each digestion stage, reported as percentages. Different lowercase and uppercase letters indicate significant differences $(P<0.05)$ among mean values among digestion phases and those among samples, respectively. 